\section{AL-AZHAR Dental Journal}

F o r

G i r
The Official Publication of The Faculty of Dental Medicine For Girls, Al-Azhar University Cairo, Egypt.

Print ISSN 2537-0308 • Online ISSN 2537-0316

ADJ-for Girls, Vol. 6, No. 4, October (2019) - PP. 453:459

\title{
Evaluation of Medicinal Plant Extract Versus Traditional Medicament Used for Vital Pulpotomy of Primary Molars
}

\author{
Safaa R. El sayed ${ }^{1 *}$, Mervat I. Fawzy ${ }^{2}$, Mohammed H. Mostafa ${ }^{3}$.
}

Codex : 55/1910

azhardentj@azhar.edu.eg

http://adjg.journals.ekb.eg

DOI: $10.21608 /$

adjg.2019.7686.1090

\section{KEYWORDS}

Ankaferd blood stopper, primary

teeth, pulpotomy, Formocresl

\begin{abstract}
Purpose: To evaluate clinically, radiographically and histologically the postoperative success of Ankaferd Blood Stopper (ABS) and formocreosl (FC) in pulpotomy procedures for primary teeth. Materials and Method: 70 Primary molars found in 27 patients were selected according to inclusion criteria. In the first part of the study pulpotomy was accomplished in 22 patients having 60 teeth (30 each group) and depending on the type of radicular pulp medicament, the teeth were divided randomly and equally into 2 groups: Group I (FC) and Group II (ABS). Clinical follow up was done after 1, 3, 6 and 9 months.Periapical radiographs were taken at 3,6 and 9 months follow up visits. In the second part of the study 10 primary molars were found in 5 patients planned for extraction due to orthodontic purpose were treated by pulpotomy procedure . Teeth were divided into 2 groups (5 each group) and the teeth were extracted after 2 months for observation under light microscope. Results: No statistically significant difference between groups in the overall cumulative clinical or radiographic success at follow up periods. Histopathological examination revealed dentin bridge formation and continuous regular arrangement of odontoblastic layer at the pulp dentin junction along the root length in primary molars treated with ABS while FC specimens revealed Severe pulp hyperemia with thrombus formation at the entrance of pulp canal. Conclusion: Ankaferd blood stopper was found to be an acceptable alternative to formocresol pulpotomy agent with less inflammatory cell response and shorter application time.
\end{abstract}

\section{INTRODUCTION}

Pulpotomy is a common therapy performed in primary molars with extensive caries and no evidence of radicular pathology. Caries removal

- Paper extracted from Doctor Thesis Titled "Evaluation of Medicinal Plant Extract Versus Traditional Medicament Used for Vital Pulpotomy of Primary Molars

1. *Assistant Lecturer of Pedodontics and Oral Health, Faculty of Dental Medicine for Girls, Al-Azhar University. Email: d.sasa.alaa@gmail.com

2. DMS, MMS, COE, Harvard University Prof. of Endodontics, Faculty of Dental Medicine for Girls, Al-Azhar University.

3. Associate Professor of Pedodontics and Oral Health, Faculty of Dental medicine for Girls, Al-Azhar University 
in these cases results in a carious or mechanical pulp exposure. The pulpotomy technique includes covering pulp stumps with a pulp capping agent to improve healing and to fix the underlying tissue ${ }^{(1)}$.

The primary teeth especially molars not treated for caries will result in the premature loss of deciduous teeth, which are at risk for the longest period. Early loss of primary teeth will lead to malocclusion, functional and esthetic problems . Therefore, preserving the vitality of deciduous teeth until their natural exfoliation time is critical for maintaining the arch integrity ${ }^{(2)}$.

The pulpotomy technique is classified into different types according to the medicaments used; the most common type is the formocresol (FC) pulpotomy $^{(3)}$. The carcinogenicity of formaldehyde is known, based on sufficient evidence from studies in humans and supporting data on mechanisms of carcinogenesis. Additional alternatives to high formaldehyde content medicaments that interface with vascularized connective tissue within the dental pulps of children must be found and used. So, several medicaments have been projected as substitutes for formocresol, with varying success ${ }^{(4)}$.

Interest in medicinal plants has burgeoned due to the increased efficacy of new plant derived drugs and the growing interest in natural products because of the concerns about the side effects of conventional medicine ${ }^{(3)}$. Alternative medicaments for use in primary molar pulpotomies, including hemostatic agents, continue to be explored. Ankaferd blood stopper(ABS) is a newly introduced hemostatic agent that combines herbal extracts obtained from five different plants;- Thymus vulgaris, Glycyrrhiza glabra, Vitis vinifera, Alpinia officinarum and Urtica dioica $^{(5)}$. The basic mechanism of action for ABS depends on the formation of an encapsulated protein network. This network formation is related to the functions of blood proteins and red blood cells. ABS could be effectively used both in individuals with normal hemostatic parameters and in patients with deficient primary and secondary hemostasis.
Some studies have shown that ABS has been safely used to control bleeding in various types of medical and dental treatment ${ }^{(6,7)}$. Therefore, the aim of this study was to evaluate and compare the clinical, radiographical and histological success of ABS and $\mathrm{FC}$ on pulpotomy treatment in primary molars.

\section{MATERIALS AND METHODS}

\section{First part of the study:}

In the first part of the study 22 patients having 60 teeth were included that fulfilled the following criteria; age from 4-8 years old, patient and parent cooperation, absence of any systemic disease that can contraindicate pulp therapy, having at least two carious primary molars with nearly equal carious involvement that will possibly require pulpotomy. The selected teeth had the following criteria; asymptomatic with a deep carious lesion, restorability with a stainless-steel crown, no pathologic signs of pulpal infection or tooth mobility, sinus tract and soft tissue swelling, no pulpal necrosis or infectious exudates after entry into the pulp chamber and attainment of radicular pulp hemostasis after compression with a sterile cotton pellet. Radiographically teeth should be without inter radicular radiolucency, no loss of lamina dura, no internal or external resorption and no widening in the periodontal ligament space.

\section{Second part of the study:}

In this part of the study 10 primary molars in 5 systemically healthy patients that aged 8-10 years old were used each had two primary molars planned for extraction due to orthodontic purpose.

Detailed medical and dental history were obtained, then clinical and radiographic examinations were carried out. Preoperative periapical radiographs of the teeth considered for treatment in the study were obtained by a standardized paralleling technique and an exposure time of 0.4 seconds. To achieve such technique, the following equipment were used: an XCP posterior film holder ,Intra oral 
sensor size 0 , an $\mathrm{X}$ ray machine set at $70 \mathrm{Kvp}, 8 \mathrm{~mA}$ and a digital xray system (Vista scan Dental Perio, Durr Dental AG, Bietigheim,Germany).

\section{Technique of vital pulpotomy:}

Teeth to be treated were locally anaesthetized using Mepecaine - L (Alexandria Co. For Pharmaceuticals, Egypt).Patients were allowed to wait for $10 \mathrm{~min}$ before pulpotomy procedure, rubber dam was used to isolate the selected tooth. After caries removal with a sterile \#330 high-speed pear-shaped carbide bur with air/water spray, access to a pulp chamber was detected with a probe, or if the roof of the pulp chamber was sufficiently thin to see the pulpal tissue. When the pulpal exposure was confirmed, the roof of the pulp chamber was removed with a sterile large high speed round bur\#4 with water spray. Coronal pulp amputation was achieved with a sterile sharp, large, spoon excavator and the access was refined with a sterile high speed fissure bur. Primary hemeostasis was attained by placing small cotton pellet moistened in sterile saline with slight pressure for 2-3 minutes. Excessive bleeding during pulp amputation or non vital teeth were excluded from this study.

For the clinical and radiographic evaluation (first part of the study), the teeth were divided randomly by numbering toss and equally into 2 groups I and II.

\section{Group I (FC) (30 primary molars):}

Pulp chamber was cleaned with physiologic saline. Acotton pellet dipped in formocresol (Prevest Dent Pro, Digiana, Jammu, India), squeezed and was placed on the pulp tissues for 5 minutes $^{(7)}$, after hemorrhage control a freshly mixed zinc oxide eugenol (Zinconol ( ${ }^{\circledR}$ Prevest Dent Pro, Digiana, Jammu, India) base was applied.

\section{Group II (ABS) (30 primary molar):}

Pulp chamber was cleaned with physiologic saline . A cotton pellet dipped in Ankaferd blood stopper solution (Ankaferd Health Products Ltd., Istanbul, Turkey), squeezed and was placed on the pulp tissues for 15 seconds $^{(7)}$. Ankaferd blood stopper was flushed away from the pulp chamber with sterile saline and a freshly mixed zinc oxide eugenol (Zinconol ® Prevest Dent Pro, Digiana, Jammu, India) base was applied.

All teeth were restored with glass ionomer restoration (EQUIA ${ }^{\mathrm{TM}}$ Fil GC corporation, Tokyo, Japan, ALSIP, IL60803) and then with stainless steel crowns (3M ESPE St Paul, USA) using glass ionomer cement (PROMEDICA Dental Material GmbH Domagkser, 31. 24537 Germany) and post operative radiograph was taken.

Patients were instructed to contact the investigator if any adverse signs or symptoms occurred between follow up visits. The children were recalled for clinical examination after 1,3,6 and 9 months, for the presence of any signs and symptoms in the treated teeth. Teeth showing the following criteria were considered as success; no symptoms of pain, no swelling of pulpal origin, no fistula, no tenderness to percussion, no pathological mobility. The clinical assessment was done at each follow up visit, data were recorded in a patient evaluation form.Periapical radiographs also were taken for all treated teeth at 3,6 and 9 months follow up visits only using the same standardized technique described before for preoperative radiographs. Teeth showing the following criteria were considered as success; no internal resorption, no pathologic external resorption, no interradicular radiolucency, no periapical radiolucency, no widening of periodontal ligament space.

\section{Second part of the study (histological study):}

In the second part of the study 10 deep carious primary molars in 5 systemically free patients were used, they were previously planned for extraction due to orthodontic purpose. 
After pulpotomy procedure had been performed as mentioned before (three teeth in each group), the treated teeth were extracted after 2 months and kept in $10 \%$ buffered formalin solution for minimum 24 hours and were decalcified in 5\% nitric acid for 3 weeks. Six-micrometer-thick sections were cut with a microtome in occlusogingival direction and stained with Hematoxylin and Eosin and viewed under light microscope. The histopathologic parameters were evaluated in terms of: Presence or absence of dentin bridge formation, odontoblastic layer continuity and inflammation.

The degree of inflammation was classified in groups from 0 to 4 as none, mild, moderate, severe or necrosis:-

0 (None): normal pulp structure (predominance of fibroblasts and collagen fibers)

1 (Mild): increased number of cells, predominately fibroblasts. Few inflammatory cells appear. Appearance of some dilated blood vessels is noted, and few extravasated red blood cells maybefound.

2 (Moderate): characterized by more chronic inflammatory cells in the area than in the mild reaction. Increased number of dilated blood vessels is found.

3 (Severe): marked inflammatory cellular infiltration, numerous severelydilated blood vessels are found in the tissue surrounding the intense cellular infiltration.

4 (Necrosis) of thepulp.

\section{Statistical analysis:}

Statistical analysis was then performed using a commercially available software program (SPSS 18; SPSS, Chicago, IL, USA).Descriptive statistics presented data as frequency and percentage. Chi square test was used for comparisons. One-way ANOVA was used to compare the mean age in different groups. The level of significance was set at $\mathrm{P}<0.05$.

\section{RESULTS}

There was no statistically significant difference between groups in the overall cumulative clinical success at 1, 3,6 and 9 months. Radiographic evaluation also showed no statistically significant difference between groups in the overall cumulative success at 3,6 and 9 months (Table 1 and Figure 1 ).

Table (1):- Radiographic evaluation at 9 months and significance of difference between both groups (chi square test)

\begin{tabular}{|c|c|c|c|c|c|c|}
\hline \multirow{2}{*}{$\begin{array}{l}\text { Radiographic } \\
\text { evaluation } \\
\text { (9 months) }\end{array}$} & \multicolumn{2}{|c|}{$\begin{array}{c}\text { Group I } \\
\text { (Formocresol) }\end{array}$} & \multicolumn{2}{|c|}{$\begin{array}{c}\text { Group II } \\
\text { (Ankaferd } \\
\text { blood } \\
\text { stopper) }\end{array}$} & \multirow[t]{2}{*}{$X^{2}$} & \multirow[t]{2}{*}{$\mathbf{P}$} \\
\hline & $\underset{(\mathbf{3 0})}{\mathbf{N}}$ & $\%$ & $\begin{array}{c}\mathbf{N} \\
(\mathbf{3 0})\end{array}$ & $\%$ & & \\
\hline $\begin{array}{l}\text { 1-Internal root } \\
\text { resorption }\end{array}$ & 1 & 3.3 & 1 & 3.3 & 0 & $1^{\mathrm{ns}}$ \\
\hline $\begin{array}{l}\text { 2-External root } \\
\text { resorption }\end{array}$ & 0 & 0 & 0 & 0 & 0 & $1^{\mathrm{ns}}$ \\
\hline $\begin{array}{l}\text { 3-Widened } \\
\text { periodontal } \\
\text { ligament }\end{array}$ & 1 & 3.3 & 2 & 6.6 & 0.35 & $0.55^{\mathrm{ns}}$ \\
\hline $\begin{array}{l}\text { 4-Periapical } \\
\text { radiolucency }\end{array}$ & 2 & 6.6 & 1 & 3.3 & 0.35 & $0.55^{\mathrm{ns}}$ \\
\hline $\begin{array}{l}\text { 5-Inter-radicular } \\
\text { bone resorption }\end{array}$ & 0 & 0 & 1 & 3.3 & 1.02 & $0.31^{\mathrm{ns}}$ \\
\hline $\begin{array}{l}\text { Radiographic } \\
\text { success }\end{array}$ & 26 & 86.7 & 25 & 83.3 & 0.13 & $0.72^{\mathrm{n}}$ \\
\hline
\end{tabular}

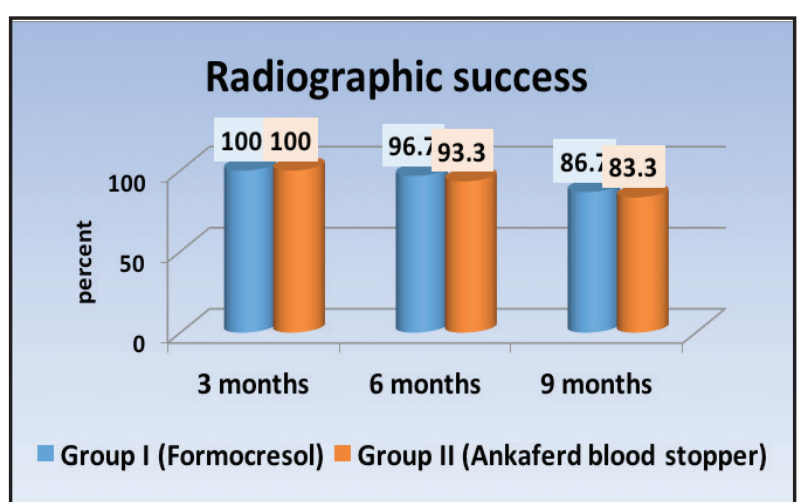

Figure 1: Column chart showing percentage of radiographic success at 3,6 and 9 months in both groups (I and II) 
Histopathologic evaluation of the specimens treated with formocresol showed Severe pulp hyperemia with thrombus formation at the entrance of pulp canal. The central part of the pulp showed hyalinization of the connective tissue stroma, interstitial edema with numerous void spaces(Fig 2). In between fibers severe dilatation of the blood vessels indicating hyperemia with extravasated red blood cells were observed. In one specimen, abscess formation was detected at deep part of the pulp tissue and surrounded by fibrosis of pulp tissue. Ankaferd blood stopper specimen revealed dentin bridge formation, continuous regular arrangement of odontoblastic layer at the pulp dentin junction along the root length and presence of scattered areas of dystrophic calcification (Fig 3). Mild degree of inflammation had also been revealed in the form of few chronic inflammatory cellular infiltration and presence of some dilated blood vessels with extravasated red blood cells in a loose fibrous connective tissue stroma.

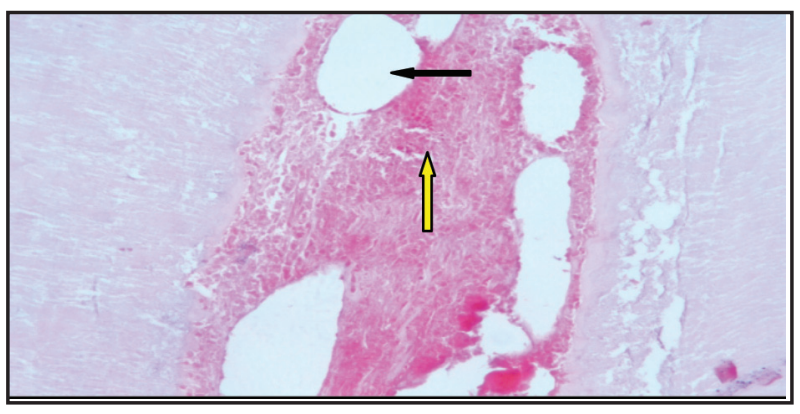

Figure 2: Photomicrograph of a section in the pulp of a primary frist molar, taken 2 months after pulpotomy done with formocresol $(100 x)$, Showing abscess formation was detected at deep part of the pulp tissue (black arrow) and fibrosis of pulp tissue (yellow arrow)

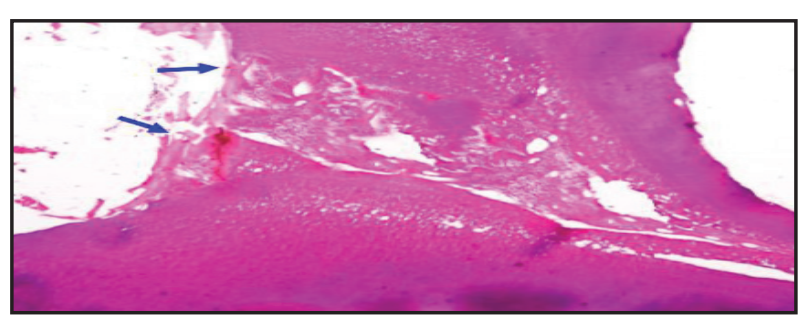

Figure3: Photomicrograph of a section in the pulp of a primary second molar, taken 2 months after pulpotomy done with ankaferd blood stopper (40x) showing dentin bridge formation at the entrance of root canal (blue arrow).

\section{DISCUSSION}

The use of plants and plant extracts for medicinal purposes has experienced remarkable advancement in recent years; similarly, the use of biocompatible substances has become a major area of interest in modern dentistry, especially when direct contact with dental tissue is necessary ${ }^{(8)}$.

Ankaferd blood stopper was chosen for this study ,as it is naturally occurring product, a newly introduced hemostatic agent that combines herbal extracts obtained from five different plants :Thymus vulgaris, Glycyrrhiza glabra, Vitis vinifera, Alpinia officinarum and Urtica dioica Each of these plants has an impact on cellular proliferation, vascular dynamics, angiogenesis, blood cells, cell mediators and endothelia ${ }^{(5,9)}$.

In Ankaferd blood stopper group, all clinical signs of failure were absent at one and 3 months . The overall clinical success was $100 \%$ at 1 and 3 months, $93.3 \%$ at 6 months and $86.7 \%$ at 9 months. The high percentage of clinical success corroborates the results of other study which showed $100 \%$ clinical success at 3 months for ABS group and 93.3\% at 6 months .At 12 month follow up, the total success ABS groups was $85.7 \%^{(10)}$. However in the current study the higher percentage was $86.7 \%$ at 9 months. This high percentage of success may be attributed to the anti-inflammatory, antibacterial potential of Ankaferd blood stopper . These results are in disagreement with a previous study which reported that: at the 3 and 6 month the clinical success rates of $100 \%$ was observed in ABS group and reduced to $90.9 \%$ at the 9 months ${ }^{(11)}$. However , this studies ${ }^{(10,11)}$ and the current study revealed that time had no statistically significant effect on the overall cumulative clinical success.

Regarding the radiographic evaluation in ABS group,all radiographic signs of failure were absent at 3 months. At 6 months, one case showed periapical radiolucency and one case showed inter-radicular bone resorption. At 9 months, one case showed internal root resorption, 2 cases showed widened 
periodontal ligament, 1 case showed periapical radiolucency and one case showed inter radicular bone resorption. The overall radiographic success was $100 \%$ at 3 months, $93.3 \%$ at 6 months and $83.3 \%$ at 9 months .These results corroborate the results of previous study which reported radiographic evaluation at 3 months revealed total success rates of $100 \%$, at 6 months was $93.3 \%$ and at the 12 -month follow-up, it was $85.7 \%{ }^{(10)}$.

In the Formocrosol group, clinical success was $100 \%$ at 1 and 3 months, $96.7 \%$ at 6 months and $90 \%$ at 9 months which revealed that time had no statistically significant effect on the overall cumulative clinical success.Regarding the radiographic evaluation, all radiographic signs of failure were absent at 3 months, $96.7 \%$ at 6 months and $86.7 \%$ at 9 month which revealed that time had no significant effect on the overall radiographic success $^{(11)}$.

Histopathologic evaluation of the specimens treated with ankaferd blood stopper revealed dentin bridge formation at pulp canal entrance, a continuous regular arrangement of odontoblastic layer at the pulp dentin junction along the root length , mild degree of inflammation had also been revealed in the form of few chronic inflammatory cellular infiltration and presence of some dilated blood vessels with extravasated red blood cells in a loose fibrous connective tissue stroma. These results corroborate the results of a pervious study which showed dentin bridge formation but only after one month as study design was performed on rats ${ }^{(\mathbf{1 2})}$.

Formocresol specimens showed severe dilatation of the blood vessels indicating hyperemia with extravasated red blood cells and thrombus formation . These results are probably due to the formaldehyde penetration into vessels causing their fixation, since formaldehyde diffusion is faster 5 times in blood plasma than in tissues ${ }^{(13)}$. In addition, fibrosis and hyalinization were revealed which are considered as fixation. This is similar to the results obtained by other studies which showed inflammation, hyaline degeneration, fibrosis and calcified masses in the formocresol treated specimen ${ }^{(14-16)}$. Abscess formation was also observed in the pulp space, this is because formocresol leaves the pulp chronically inflamed which increase the susceptibility of abscess formation ${ }^{(17)}$. This finding is similar to an earlier study which reported abscess formation in pulp treated with formocresol ${ }^{(18)}$.

\section{CONCLUSION}

Ankaferd blood stopper was found to be an acceptable alternative to formocresol pulpotomy agent with less inflammatory cell response and shorter application time.

\section{REFRENCES}

1. Winters J , Cameron A ,Widmer R . Pulp therapy for primary and immature permanent teeth.Handbook of Pediatric Dentistry ( $\left.4^{\text {th }} \mathrm{ed}\right), 2013 ; 103-22$.

2. Fuks ABKA, Guelmann M. Pulp therapy for the primary dentition .Pediatric dentistry infancy through adolescence. St Louis, Missouri: Elsevier Saunders. 2013;2; 333-51.

3. Waterhouse PJ.Formocresol and alternative primary molar pulpotomy medicaments: A review. Endod Dent Trauma 1995;11:157-62.

4. K B. Pulpotomy in primary teeth-A review.J Indian Acad Dent Spe. 2011;2,29-31.

5. Uğur A, Saraç N, Çankal DA, Özle M.:-The antioxidant and antimutagenic activities of Ankaferd blood stopper,a natural hemostatic agent used in dentistry. Turk J Med Sci. 2016;46:657-63.

6. Guler M, Maralcan G, Kul S, Baskonus I, Yilmaz M. The efficacy of Ankaferd Blood Stopper for the management of bleeding following total thyroidectomy. J Invest Surg 2011; 24:205-10.

7. Odabaş ME, Cinar C, Tulunoğlu O, Işik B. A new hemostatic agent's effect on the success of calcium hydroxide pulpotomy in primary molars. Pediatr Dent 2011; 33:529-34.

8. Lima RV, Esmeraldo MR, de Carvalho MG, de Oliveira PT, de Carvalho RA, da Silva FL Jr, et al. Pulp repair after pulpotomy using different pulp capping agents: A comparative histologic analysis. Pediatr Dent. 2011;33:14-8. 
9. Cinar C, Odabaş ME, Akca G, Işik B. Antibacterial effect of a new haemostatic agent on oral microorganisms. J Clin Exp Dent. 2012;4:151-5 .

10. Yaman E, Görken F, Pinar Erdem A, Sepet E, Aytepe Z; . Effects of folk medicinal plant extract Ankaferd Blood Stopper ${ }^{\circledR}$ in vital primary molar pulpotomy. Eur Arch Paediatr Dent .2012;13:197-202.

11. Cantekin C and Gümüş H: -, Success Rates of Ankaferd Blood Stopper and Ferric Sulfate as Pulpotomy Agents in Primary Molar, Int Scholarly Res Notices.2014 ;2014; 6.

12. Koyuturk AE, Tunç ES, Bayrak S, Ayas B, Özmen B, Korkmaz A. Histological evaluation of Ankaferd blood stopper, ferric sulfate and formocresol as pulpotomy agents in rat molars. J Pediatr Dent .2013;1:32-6.

13. Berger JE. A review of the erroneously labeled mummification techniques of pulp therapy, Oral sur Oral Med Oral . 1972;34:131-44.
14. Cengiz S, Airwaybill Y, Atilla P, Asan E. Histological comparison of alendronate, calcium hydroxide and formocresol in amputated rat molar. Dent Trauma 2005; 21:281-6.

15. Salako N, Joseph B, Ritwik P, Salonen J, John P, Junaid TA. Comparison of bioactive glass, mineral trioxide aggregate, ferric sulfate, and formocresol as pulpotomy agents in rat molar. Dent Traumatol 2003; 19: 314-20.

16. Jose, Ratnakumari N, Mohanty M .Calcium phosphate cement as an alternative for formocresol in primary teeth pulpotomies.Indian J Dent. 2013;24:522-6.

17. Ranly DM. Pulpotomy therapy in primary teeth: New modalities for old rationales.J Clin Pediatr Dent 1994;16:403-9.

18. Omar OM, Khattab NM, Khater DS. Nigella Sativa oil as a pulp medicament for pulpotomized teeth: a histopathological evaluation. J Clin Pediatr Dent 2012; 36: 335-42. 